\title{
Uneven frequency of Vibrio alginolyticus-group isolates among different populations of Galápagos marine iguana (Amblyrhynchus cristatus)
}

\author{
Maria C. Thaller,1* Marco Ciambotta,1, Manuela Sapochetti,1 Luciana Migliore,1, Whashington Tapia,2 Virna \\ Cedeño ${ }_{3}$ and Gabriele Gentile 1 \\ 1 Dipartimento di Biologia, Università di Roma 'Tor Vergata', Roma, Italy, ${ }_{2} P N G$, Parque National de Galapagos, Puerto \\ Ayora -Galapágos, Ecuador.sLaboratorio de Epidemiología, Parasitología y Genetica'F. Valverde', PNG, Puerto Ayora - \\ Galapágos, Ecuador.
}

Abstract The presence of Vibrio isolates was investigated in cloacal swabs from the Galápagos marine iguana (Amblyrhyncus cristatus). Such unique iguana is endemic to the Galápagos Archipelago, it is listed as vulnerable in the IUCN Red List (2009), and is strictly protected by CITES and Ecuador laws. Our results revealed an uneven isolation frequency of vibrios from animals living in different settings: maximal among the Santa Fe population, scarce at Bahía Tortuga but practically absent in the samples from Puerto Ayora and Plaza Sur. A 16S sequencing confirmed that the isolates belonged to the genus Vibrio, placing them within the $V$. alginolyticus group; the biochemical identification was, indeed, consistent with $V$. alginolyticus features. The reason of the observed discrepancy is not clear, but could be either linked to a higher pollution in the inhabited or more touristic places or to differential influence of chemical and physical parameters at a local scale. As $V$. alginolyticus is an opportunistic pathogen for man and it is known to cause disease in sea-living animals, the ability of these vibrios to enter and persist to a certain extent in the marine iguana gut should be regarded as a risk for health of both the animals and the human personnel involved in monitoring activities.

\section{Introduction}

The genus Vibrio encompasses more than 70 recognized species, mostly found in marine environments including coastal waters, and sediments, estuaries and aquaculture settings (Thompson et al., 2003). Vibrios have been demonstrated to reach high densities when associated to the surface and/or interiors of marine organisms such as clams (Sawabe et al., 2003), fish (Arias et al., 1995; Grisez et al., 1997; Huys et al., 2001), corals (Rosenberg and Ben-Haim, 2002), copepods (Huq et al., 1983; Montanari et al., 1999; Turner et al., 2009) and other zooplankton organisms (Baffone et al., 2006; Heidelberg et al., 2002; Johnson and Shunk, 1936; Suantika et al., 2001; Verdonck et al., 1994, 1997; Ringo and Birkbeck, 1999), shrimps (Gomez et al., 1998 Vandenberghe et al., 1998, 1999), Chironomus egg masses (Broza et al., 2005), sponges and seagrasses (Stabili et al., 2008; Wang et al., 2008). Such a wide range of interactions is linked to the genome plasticity (Rowe-Magnus et al., 2002) and flexible physiology, that allow vibrios to 
survive, thrive and persist in several settings of environmental conditions; the same flexibility accounts for their high efficiency in coping with global climate changes (Lipp et al., 2002).

Some species are able to cause disease in humans and sea-living animals (Chakraborty et al., 1997) and seem to enhance their pathogenicity potential as the sea-water temperature increases (Kushmaro et al., 2001; Martin et al., 2002; Rosenberg and Ben-Haim. 2002; Sechi et al., 2000).

The widespread presence of vibrios in marine environments, the ability of these microorganisms to live on marine animals or in their gut prompted us to start an investigation aimed at assessing the presence and/or isolation frequency of Vibrio species from the gut of Amblyrhyncus cristatus, the Galápagos marine iguana. In fact, no data are available for this reptile, among the most representative animal species of the Galápagos Islands. A. cristatus is endemic to the Galápagos, where it is widespread in all major islands and several islets; it is listed as vulnerable in the IUCN red List (2009) and is also strictly protected by the Convention on International Trade in Endangered Species (CITES) and Ecuadorian laws.

Both males and females show high fidelity to breeding sites, although, as a consequence of feeding behavior, males might be susceptible to some dispersal (Rassmann et al., 1997; Wikelski \& Trillmich, 1997; Romero \& Wikelski, 2001). In fact, marine iguanas gather all of their food in red or green algae mats of the intertidal zone, exposed during the low tide; only the largest individuals (mostly males, $\sim 5 \%$ of each population) are able to dive and reach the submerged subtidal algae (Hobson, 1965; Wikelski and Hau, 1995) Wikelski and Trillmich, 1994). As for strictly herbivorous animals, marine iguanas' digestion is assisted by hindgut-associated fermenting bacteria, mainly anaerobes, able to hydrolyze algae cell walls (Mackie et al., 2004).

The Galápagos are volcanic islands located in the Pacific Ocean, about 1,000 km West of coast of Ecuador, and they have never been connected to the mainland. Despite their isolation, several human settlements have been established in some islands. This archipelago was recently inscribed in the list of World Heritage in Danger (UNESCO, 2007). Thus, it is interesting to investigate what 
species of Vibrio might occur and whether its/their isolation frequency might correlate with the presence of human settlements. 


\section{Results and discussion}

\section{Screening for culturable vibrios}

The presence of vibrios was investigated on four Amblyrhynchus populations living in different sites: two were located in Santa Cruz Island (Puerto Ayora and Bahìa Tortuga, respectively) and the other two in Santa Fe and Plaza Sur islands (Fig. 1).

The four sampling sites have different characteristics: Santa Cruz (986 km²) is a large dormant volcano and harbours the largest (several thousand people) human population in the archipelago; Puerto Ayora (PA) is the coastal town with an active touristic harbor, well within Academy Bay, supposed to be the most impacted costal site in Santa Cruz. Tortuga Bay (TB) is a touristic beach on the coast just $2.5 \mathrm{~km}$ west of Puerto Ayora. As it is located outside Academy Bay, human impact is supposed to be minor. Plaza Sur (PS) is a very small $\left(0.13 \mathrm{~km}^{2}\right)$ island east of Santa Cruz, opened to tourism; at this site a huge colony of sea lions (Zalophus californianus wollebaeki) can be found. Santa Fe (SF) is a small island $\left(24 \mathrm{~km}^{2}\right)$, south-east of Santa Cruz, not inhabited by humans, where tourists can access only during daily excursions, following a restricted itinerary along short trails; Santa Fe hosts several stable groups of marine iguanas, located in correspondence of site where trophic resources are mostly available; the closest human settlement is Puerto Ayora, about $30 \mathrm{~km}$ far.

The presence of vibrios in the four samples sites was uneven (Fig. 2A). The samples from PA and PS (IMPA and IMPS; IM = Iguana Marina) exhibited a slight grow of little, mostly green colonies and quite no large colonies with Vibrio features were detected, with the only exception of an isolated sucrose positive colony in a IMPA sample. In the samples from TB (IMTB), the isolation frequency of vibrio-featuring colonies was higher (18.7\%) but the highest frequency was observed in SF samples (IMSF) with 47\% of positive samples; all of the isolates from both SF and TB sampling sites were sucrose positive ones. Another striking difference among the sampled sites, was the relative abundance of the vibrio-like colonies, scarce (1-3/plate) in the IMTB samples, as compared with other morphologies, and higher in the IMSF samples, where the possible Vibrio 
colonies were 11-25 colonies/plate and other morphologies were poorly represented. In Santa Fe, the sampled population of marine iguanas lives in strict contact with a large colony of $Z$. californianus wollebaeki, so that fecal samples were obtained from sea lions too, to verify if the observed larger isolation frequency could be biased by the habitat sharing with the fish-eating mammals. Out of thirty samples collected, however, only three showed the presence of sporadic vibrio-like colonies with features similar to the marine iguana isolates. The three sea lions (SL) isolates were picked and transferred to Italy, together with pure cultures of one isolate for each observed colony morphology from marine iguana samples.

To verify whether similar differences would concern other microbial populations in the cloaca of marine iguanas or not, we also looked for the dominant Enterobacteriaceae species in the same samples. Enterobacteria were more evenly distributed among animals in the sampled sites, Salmonella enterica and E. coli being the most represented ones in all the animal populations. In the adjacent, more anthropized sites PA and TB, S. enterica and E. coli were quite equally represented, whilst in IMPS and IMSF samples Salmonella overcame E. coli, being 70 and 64\% versus 18 and 14\%, respectively (Fig. 2B). The less represented species included Serratia spp, 1 isolate from TB and 2 from both PS and SF; Citrobacter sedlakii, 2 isolates in PA; Leclercia adecarboxylata, 2 isolates in SF; Yersinia ruckeri 1 and 2 isolates found in PS and SF, respectively.

\section{Biochemical and molecular characterization of the Vibrio isolates.}

In Italy, the isolates were plated on marine agar, were most of the tiny green colonies, were found to be light-orange pigmented, a few produced a diffusible brown pigment. All of these were oxidase positive, non fermenting bacteria; 12 isolates of the orange pigmented isolates and two of the brown pigmented ones, randomly chosen, were subjected to $16 \mathrm{~S}$ sequencing and analyzed with the Classifier program at the Ribosomal Database Project site, that identified them as Shewanella, and “unclassified Alteromonadales”, respectively. The presumptive vibrios (a total of 24 strains) gave creamy and large colonies and were examined for cell morphology and motility, Gram stain, 
oxidase and glucose fermentation; all of them were consistent with Vibrio general characteristics and were subjected to a further characterization with Api20E, Api50CH and conventional testing (Tab. 1). The results were used to follow the set of dichotomous keys proposed by Noguerola and Blanch (2007); the PA isolate was identified as Vibrio orientalis while the IMSF and IMTB isolates were partitioned into three phenotypic profiles, all of which assigned to $V$. alginolyticus. 16S amplimers were obtained from IMSF, IMTB and SL isolates, in order to investigate the possible clonal origin for the larger clusters.

An analysis with clustalW (Thompson et al., 1994) revealed a very high homology among all the IM- and SL- isolates, whose 16S sequencies formed four close clusters sharing a 99\% homology with both V. alginolyticus and V. parahaemolyticus (see Supporting Information). A phylogenetic tree (Fig. 3) was constructed with one sequence belonging to the each of the four detected clusters. Although Galápagos vibrios are not clonal, they cluster in a very well characterized group, which is phylogenetically very close to $V$. alginolyticus; they are biochemically undistinguishable from this species. The uneven distribution we have found suggests that (i) these vibrios are not part of the resident microbiota of marine iguanas and (ii) their presence most probably relates to environmental conditions, with Galápagos marine waters acting as the reservoir.

Despite the number of sites investigated is limited, our results indicate heterogeneity in terms of both presence/absence and frequency of Vibrio isolates. In this regard, the case of Puerto Ayora is instructive: the lack of isolates (with the only exception of a $V$. orientalis single colony) supports the findings from Simidu et al. (1977), who demonstrated the absence of Vibrio from marine waters within Tokyo Bay, as a consequence of human impact.

The observed heterogeneity may also be a reflection of spatial and temporal local variations in the chemical and physical parameters of sea waters surrounding Galápagos that has been observed by the Center for Galàpagos studies using time-series satellite imagery (http://galapagos.unc.edu/research/snapshots/ongoing-project-descriptions/water_quality). 
This hypothesis seems to be supported by the distribution of Enterobacteriaceae species within marine iguanas from the different sampling sites. This is more homogeneous and most probably reflecting human proximity where E. coli frequency is higher, while it is shifted towards Salmonella in the wild status. Therefore, the different incidence of Vibrio could actually be directly influenced by water quality.

Further studies will clarify the dynamics through which heterogeneity originates, accounting for spatial and temporal implications. These studies would be very important to assess the level of propagation among marine iguanas and/or other Galapagos wildlife, together with the potential concerns for personnel involved in their managing.

\section{REFERENCES}

Alsina, M. and Blanch, A.R. (1994) Improvement and update of set of keys for biochemical identification of environmental Vibrio species. Journal of Applied Bacteriology 77, 719-721.

Arias, C.R., Garay E., and Aznar R. (1995) Nested PCR method for rapid and sensitive detection of Vibrio vulnificus in fish, sediments, and water. Appl Environ Microbiol 61: 3476-3478.

Baffone, W., Tarsi, R., Pane, L., Campana, R., Repetto, B., Mariottini, G.L., and Pruzzo, C. (2006) Detection of free-living and plankton-bound vibrios in coastal waters of the Adriatic Sea (Italy) and study of their pathogenicity-associated properties. Environ Microbiol 8: 1299-1305.

Broza, M., Gancz, H., Halpern, M., and Kashi, Y. (2005) Adult non-biting midges: possible windborne carriers of Vibrio cholerae non-O1 non-O139. Environ Microbiol 7: 576-585.

Cary, S.G., and Blair, E.B. (1964) New transport medium for shipment of clinical specimens. I. Fecal specimens. J Bacteriol 88: 96-98.

Chakraborty, S., Nair, G.B., and Shinoda, S. (1997) Pathogenic vibrios in the natural aquatic environment. Rev Environ Health 12: 63-80.

DeWitt W.E, Gangarosa E.J., Hug I., Zarifi A. (1971) Holding media for the transport of Vibrio cholerae from field to laboratory. Am J Trop Med Hyg. 20: 685-688.

Farmer, J.J. III, and Hickman-Brenner, F.W. (2006) The genera Vibrio and Photobacterium. In: The Prokaryotes, $3^{\text {rd }}$ ed. (Dworkin, M., et al., eds.), Vol. 6, pp. 508-563.

Gomez-Gil, B., Roque, A., Turnbull, J.F., and Tron-Mayen, L. (1998) Species of Vibrio isolated from hepatopancreas, haemolymph and digestive tract of a population of healthy juvenile Penaeus vannamei. Aquaculture 163: 1-9. 
Grisez, L., Reyniers, J., Verdonck, L., Swings, J., and Ollevier, F. (1997) Dominant intestinal microflora of sea bream and sea bass larvae from two hatcheries, during larval development. Aquaculture 155: 387-399.

Heidelberg, J.F., Heidelberg, K.B., and Colwell, R.R. (2002) Bacteria of the gamma-subclass Proteobacteria associated with zooplankton in Chesapeake Bay. Appl Environ Microbiol 68: 54985507.

Hobson, E.S. (1965) Observations on diving in the Galapagos marine iguana, Amblyrhynchus cristatus (Bell). Copeia 1965: 249-250.

Huq, A., Small, E.B., West, P.A., Huq, M.I., Rahman, R., Colwell, R.R. (1983) Ecological relationships between Vibrio cholerae and planktonic crustacean copepods. Appl Environ Microbiol 45: 275-283.

Huys, L., Dhert, P., Robles, R., Ollevier, F., Sorgeloos, P., and Swings, J. (2001) Search for beneficial bacterial strains for turbot (Scophthalmus maximus L.) larviculture. Aquaculture 193: 2537.

Johnson, F.H., and Shunk, I.V. (1936) An interesting new species of luminous bacteria. J Bacteriol 31: 585-593.

Kushmaro, A., Banin, E., Loya, Y., Stackebrandt, E., and Rosenberg, E. (2001) Vibrio shiloi sp. nov., the causative agent of bleaching of the coral Oculina patagonica. Int J Syst Evol Microbiol 51: $1-6$.

Lipp E. K., Huq A. and Colwell R. R. (2002) Effects of global climate on infectious disease: the cholera model. Clin. Microbiol. Rev. 15: 757-770.

MacDonell, M.T., Singleton, F.L., and Hood, M.A. (1982) Diluent composition for use of API 20E in characterizing marine and estuarine bacteria. Appl Environ Microbiol, 44: 423-427.

Mackie, R.I., Rycyk, M., Ruemmler, R.L., Aminov, R.I., and Wikelski M. (2004) Biochemical and microbiological evidence for fermentative digestion in free-living land iguanas (Conolophus pallidus) and marine iguanas (Amblyrhynchus cristatus) on the Galapagos archipelago. Phys Biochem Zool 77: 127-38.

Martin, Y., Bonnefont, J.L., and Chancerelle, L. (2002) Gorgonians mass mortality during the 1999 late summer in French Mediterranean coastal waters: the bacterial hypothesis. Water Research 36: 779-782.

Montanari, M.P., Pruzzo, C., Pane, L., and Colwell, R.R. (1999) Vibrios associated with plankton in a coastal zone of the Adriatic Sea (Italy). FEMS Microbiol Ecol 29: 241-247.

Murray, P. (2003) Manual of Clinical Microbiology, $8^{\text {th }}$ ed., ASM Press, Washington DC.

Noguerola, I., and Blanch, A.R. (2008) Identification of Vibrio spp. with a set of dichotomous keys. J Appl Microbiol 105: 175-185.

Rassmann, K., Tautz, D., Trillmich, F., Gliddon C. (1997) The microevolution of the Galápagos marine iguana Amblyrhynchus cristatus assessed by nuclear and mitochondrial genetic analyses. Mol Ecol 6: 437-452. 
Ringo, E., and Birkbeck, T.H. (1999) Intestinal microflora of fish larvae and fry. Aquaculture Res 30: 73-93.

Romero, L. M. \& Wikelski, M. (2001) Corticosterone levels predict survival probabilities of Galapagos marine iguanas during El Niño event. Proc. Natl Acad. Sci. USA 98: 7366-7370.

Rosenberg, E., Ben-Haim Y. (2002) Microbial diseases of corals and global warming. Environ Microbiol 4: 318-326.

Rowe-Magnus, D.A., Guerout, A.M., and Mazel, D. (2002) Bacterial resistance evolution by recruitment of super-integron gene cassettes. Mol Microbiol 43: 1657-1669.

Sawabe, T., Setogushi, N., Inoue, S., Tanaka, R., Ootsubo, M., Yoshimizu M., and Ezura, Y. (2003) Acetic acid production of Vibrio halioticoli from alginate: a possible role for establishment of abalone-V. halioticoli association. Aquaculture 219: 671-679.

Sechi, L.A., Duprè, I., Deriu, A., Fadda, G., and Zanetti, S. (2000) Distribution of Vibrio cholerae virulence genes among different Vibrio species isolated in Sardinia, Italy. J Appl Microbiol 88: 475-481.

Simidu, U., Kaneko, E., and Taga, N. (1977) Microbiological studies of Tokyo Bay. Microb Ecol 3: 173-191.

Stabili, L., Licciano, M., Longo, C., Corriero, G., and Mercurio, M. (2008) Evaluation of microbiological accumulation capability of the commercial sponge Spongia officinalis var. adriatica (Schmidt) (Porifera, Demospongiae). Water Research 42: 2499-2506.

Suantika, G., Dhert, P., Rombaut, G., Vandenberghe, J., De Wolf, T., and Sorgeloos, P. (2001) The use of ozone in a high-density recirculation system for rotifers. Aquaculture 201: 35-49.

Thompson, F.L., Iida, T., Swings, J. (2003) Biodiversity of vibrios. Microbiol Mol Biol Rev 68: 403-431.

Thompson, J.D., Higgins, D.G., Gibson T.J. (1994) Nucleic Acids Res 22: 4673-4680.

Turner, J.W., Good, B.,Cole, D., and Lipp, E.K. (2009) Plankton composition and environmental factors contribute to Vibrio seasonality ISME J 3: 1082-1092.

UNESCO (2007) Galapagos Islands added to the World Heritage Danger List. [WWW document]. URL http://www.iucn.org/search.cfm?uSearchTerm=galapagos (accessed September 2009).

Vandenberghe, J., Li, Y., Verdonck, L., Li, J., Sorgeloos, P., Xu, H.S., and Swings, J. (1998) Vibrios associated with Penaeus chinensis (Crustacea: Decapoda) larvae in Chinese shrimp hatcheries. Aquaculture 169: 121-132.

Vandenberghe, J., Thompson, F.L., Gomez-Gil, B., and Swings, J. (2003) Phenotypic diversity amongst Vibrio isolates from marine aquaculture systems. Aquaculture 219: 9-20.

Vandenberghe, J., Verdonck, L., Robles-Arozarena, R., Rivera, G., Bolland, A., Balladares, B., Gomez-Gil, M., Calderon, J., Sorgeloos, P., and Swings, J. (1999) Vibrios associated with Litopenaeus vannamei larvae, postlarvae, broodstock, and hatchery probionts. Appl Environ Microbiol 65: 2592-2597. 
Verdonck, L., Grisez, L., Sweetman, E., Minkoff, G., Sorgeloos, P., Ollevier, F., and Swings, J. (1997) Vibrios associated with routine productions of Brachionus plicatilis. Aquaculture 149: 203214.

Verdonck, L., Swings, J., Kersters, K., Dehasque, M., Sorgeloos, P., and Leger, P. (1994) Variability of the microbial environment of rotifer Brachionis plicatilis and Artemia production systems. J World Aquacult Soc 25: 55-59.

Wang G., Yoon, S.-H., and Lefait, E. (2008) Microbial communities associated with the invasive Hawaiian sponge Mycale armata. ISME J 3: 374-377.

Wikelski, M., and Hau, M. (1995) Is there an endogenous tidal foraging rhythm in marine iguanas? J Biol Rhythm 10: 345-360.

Wikelski, M., and Romero, L.M. (2003) Body size, performance and fitness in Galapagos marine iguanas. Integr. Compar. Biology 43: 376-386.

Wikelski, M., and Trillmich, F. (1994) Foraging strategies of the Galápagos marine iguana (Amblyrhynchus cristatus): adapting behavioral rules to ontogenetic size change. Behaviour 128: 255-279.

Wikelski, M., and Trillmich, F. (1997) Body size and sexual dimorphism in marine iguanas flactuate as a result of opposing natural and sexual selection: an island comparison. Evolution 51: 922-936. 


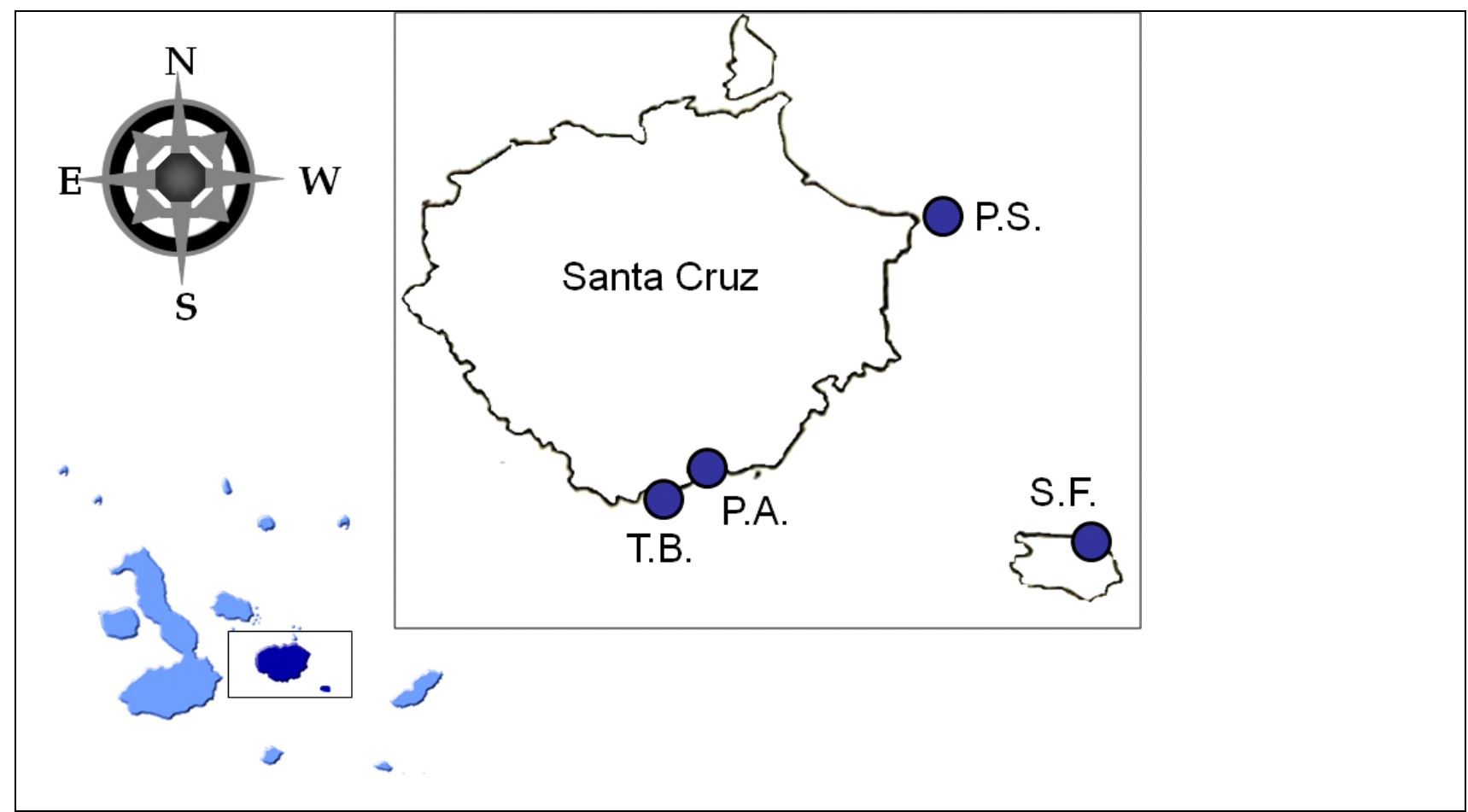

Fig-1 PA, Puerto Ayora; PS, Plaza Sur; SF, Santa Fe; TB, Bahìa Tortuga. (Adapted and redrawn from both: Perry-Castañeda Library Map collection (Galapagos Central group, Map of Hispanic America, 1927), and Michael H. Jackson, (Galapagos: A Natural History Guide, ). 


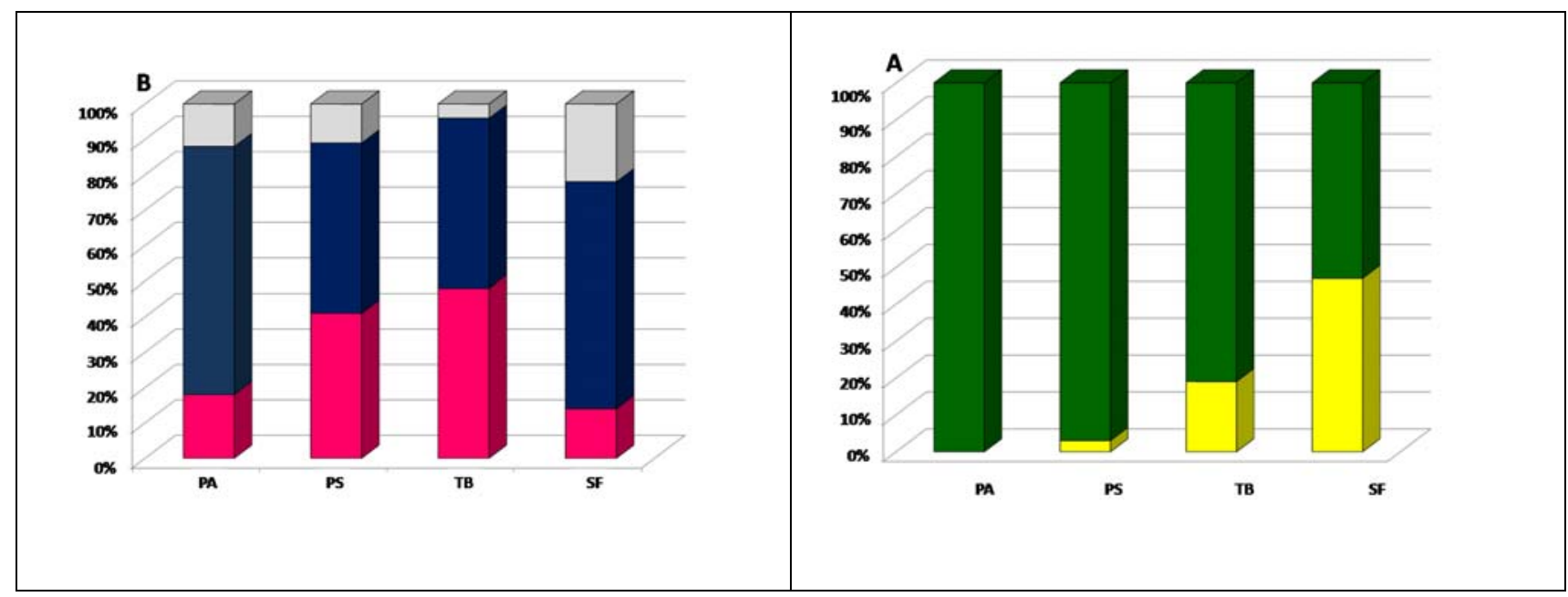

Fig. 2 The sampling was performed in July, 2005, on thirty animals out of each examined population. Sterile transport swabs with Cary Blair medium (COPAN Diagnostics Inc.) were used to assure the survival of the strains during the transfer to laboratory (DeWitt et al., 1971). The samples were taken from immobilized iguanas, by inserting the swab about $5 \mathrm{~cm}$ inside the cloacal orifice.

The cloacal swabs were then transferred within a week to the Charles Darwin Station laboratory. Swabs were streaked onto both TCBS and MacConkey plates (Oxoid), which were inspected for growth after an overnight incubation at $25^{\circ} \mathrm{C}$ and $35^{\circ} \mathrm{C}$, respectively. Among the colonies grown on TCBS, the large, healthy and fast growing ones were regarded as possible vibrios.

One colony for each observed morphology on both the selective media was picked, checked for purity, inoculated in Wheaton vials filled with Cary Blair medium (Cary and Blair, 1964) and transferred to Italy. In Italy cultures were plated onto marine agar (Difco) and Trytpicase Soy Agar (Difco) respectively, and then stored in Skim milk 10\% (Oxoid; Farmer and Hickman-Brenner, 2006) at $-70^{\circ} \mathrm{C}$ until the study took place. 


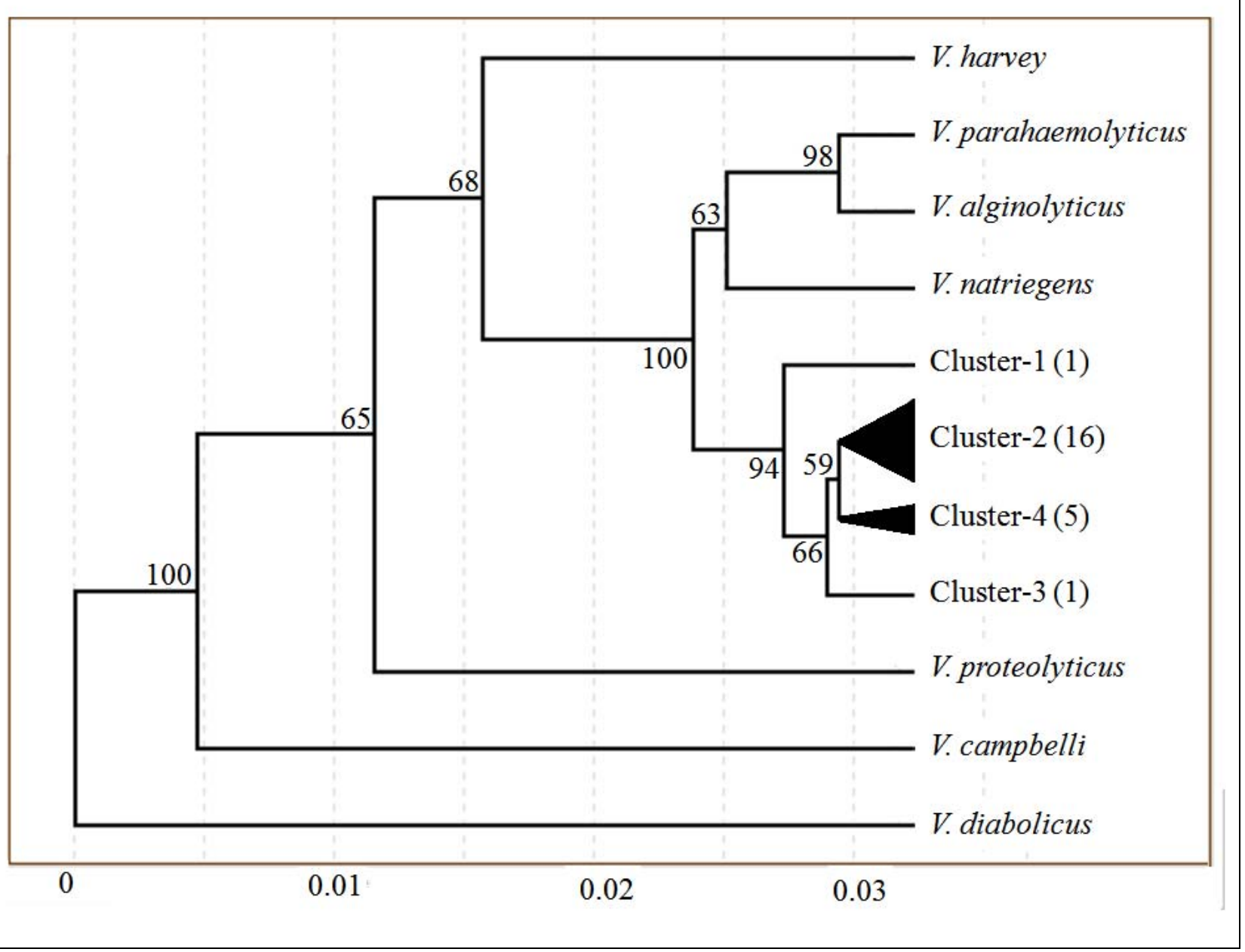

Fig-3 V. harveyi ${ }^{T}$,ATCC 14126 (X74706); V. parahaemolyticus ${ }^{\mathrm{T}}$; ATCC 17802T (X74720); V. alginolyticus $^{T}$; ATCC 17749(X74690); V. natriegens ${ }^{T}$, ATCC 14048T (X74714); V. proteolyticus ${ }^{\mathrm{T}}$, ATCC 15338(X74723); V. campbellii ${ }^{\mathrm{T}}$; ATCC 25920 (X56575; V. diabolicus ${ }^{\mathrm{T}}$, HE800(X99762).

Species to be included in the tree were chosen according to the SeqMatch program results, at the Ribosomal Database Project site; ClustaW was performed at the Pôle Bioinformatique Lyonnais website http://npsa-pbil.ibcp.fr/NPSA/npsa_clustalwan.html; the phylogenetic tree was constructed based on the "cluster algorithm”, as implemented in the program TreeTop, available on line at the GeneBee (Brodsky et al., 1992) website: http://www.genebee.msu.su/genebee.html. Bootstrap values are shown in the Figure. Experimental sequenced obtained in this work have been submitted to GenBank (Submissions from GQ907021 to GQ907043). All the aligned fragments had the same length, corresponding to the 53-1427 region of $V$. alginolyticus $^{T}$ sequence X74690. 



\begin{tabular}{|c|c|c|c|c|c|c|c|c|c|c|}
\hline Profile & Isolates (n) & $40^{\circ} \mathrm{C}$ & $\mathrm{NaCl} 10 \%$ & Swarming & ONPG & OD & GAL & MNE & MEL & Identification \\
\hline A & IMPA (1) & 0 & 0 & 0 & 1 & 0 & 1 & 1 & 1 & $V$. orientalis \\
\hline \multirow[t]{3}{*}{$\mathrm{B}$} & IMSF (8) & 1 & 1 & 1 & 0 & 0 & 0 & 1 & 0 & V. alginolyticus \\
\hline & IMTB (4) & & & & & & & & & \\
\hline & SL (1) & & & & & & & & & \\
\hline $\mathrm{C}$ & IMSF (2) & 1 & 1 & 1 & 0 & 0 & 0 & & & V. alginolyticus \\
\hline $\mathrm{D}$ & SL(1) & 1 & 1 & 1 & 0 & 0 & 0 & & & V. alginolyticus \\
\hline $\mathrm{E}$ & IMSF (1) & 1 & 1 & 1 & 0 & 0 & 1 & & & V. alginolyticus \\
\hline \multirow[t]{2}{*}{$\mathrm{F}$} & IMSF (2) & 1 & 1 & 1 & 0 & 1 & 0 & & & V. alginolyticus \\
\hline & IMTB (1) & & & & & & & & & \\
\hline
\end{tabular}

Identification was performed with Api 20E and Api 50CH strips, and additional tests described by Alsina and Blanch (1994). The suspension medium for Api 20E was marine salts 2\% (MacDonell et al., 1982); a saturated solution of NaCl was added to Api50 CHE medium, to reach a final concentration of about $1.8 \%$. Incubation temperature for the enzymatic test and $\mathrm{NaCl}$ tolerance was $30^{\circ} \mathrm{C}$; the tests were read daily for 3 days. Growth at different temperatures was determined in TSB medium added with $1.5 \% \mathrm{NaCl}$. All of the isolates yielded positive results for oxydase, indole, NO3 reduction, lysine decarboxylase; growth at $22^{\circ} \mathrm{C}, 30^{\circ} \mathrm{C}, 35^{\circ} \mathrm{C}$ and at $3 \%, 6 \%, 8 \% \mathrm{NaCl}$; indole; gelatinase; fermentation of $\mathrm{D}$-fructose, D-glucose, D-maltose, glucose, glycerol, glycogen, mannitol, $N$-acetylglucosamine, potassium gluconate, starch and sucrose. The following tests yielded negative results for all the tested isolates: growth at $0 \% \mathrm{NaCl}$; urease; phenylalanine deaminase; VogesProskauer; arginine dihydrolase; aesculin hydrolysis; acid from: amygdalin, arbutin, D-adonitol, D- and L-arabinose, D- and L-arabitol, D- and L-fucose, dulcitol, erythritol, gentobiose, inositol, inulin, D-lactose, D-lyxose, melezitose, methyl-bDxylopyranoside, methyl-a-D-glucopyranoside, methyl-a-Dmannopyranoside, potassium 2-ketogluconate, potassium 5-ketogluconate, D-raffinose, D-ribose, L-rhamnose, D-sorbitol, L-sorbose, D-tagatose, D-turanose, salicin, xylitol, D- and L-xylose. OD; ornithyne decarboxylase; GAL, D-galactose; MNE, D-mannose; MEL, D-melibiose. 